\title{
Protecting-Group-Free Site-Selective Reactions in a Metal-Organic Framework Reaction Vessel
}

\author{
Michael. T. Huxley, ${ }^{\mathrm{a}}$ Alexandre Burgun, ${ }^{\mathrm{a}}$ Hanieh Ghodrati, ${ }^{\mathrm{a}, \mathrm{b}}$ Campbell J. Coghlan, ${ }^{\mathrm{a}}$ Anthony \\ Lemieux, ${ }^{a}$ Neil R. Champness, ${ }^{\mathrm{c}}$ David M. Huang, ${ }^{\mathrm{a}}$ Christian J. Doonan*a and Christopher J. Sumby*a \\ a Department of Chemistry and Centre for Advanced Nanomaterials, The University of Adelaide, Adelaide, South Australia \\ 5005, Australia; E-mail: christopher.sumby@adelaide.edu.au; E-mail: christian.doonan@adelaide.edu.au \\ b Present address: School of Mechanical Engineering, University of Adelaide, Adelaide, South Australia 5005, Australia \\ c Department of Chemistry, University of Nottingham, Nottingham, UK
}

KEYWORDS. Metal-Organic Frameworks, Azide-alkyne cycloaddition, Site-selective chemistry, single-crystal to single-crystal transformations

\begin{abstract}
Site-selective organic transformations are commonly required in the synthesis of complex molecules. By employing a bespoke metal-organic framework $\left(\mathrm{MOF}, \mathbf{1} \cdot\left[\mathrm{Mn}(\mathrm{CO})_{3} \mathrm{~N}_{3}\right]\right.$ ), in which coordinated azide anions are precisely positioned within $1 \mathrm{D}$ channels, we present a strategy for the site-selective transformation of dialkynes into alkyne-functionalized triazoles. As an illustration of this approach, 1,7-octadiyne-3,6-dione stoichiometrically furnishes the mono-“click" product $N$-methyl-4-hex-5'-ynl-1',4'dione-1,2,3-triazole with only trace bis-triazole side-product. Stepwise insights into conversions of the MOF reaction vessel were obtained by X-ray crystallography, demonstrating that the reactive sites are "isolated" from one another. Single-crystal to singlecrystal transformations of the $\mathrm{Mn}(\mathrm{I})$-metalated material $\mathbf{1} \cdot\left[\mathrm{Mn}(\mathrm{CO})_{3}\left(\mathrm{H}_{2} \mathrm{O}\right)\right] \mathrm{Br}$ to the corresponding azide species $\mathbf{1} \cdot\left[\mathrm{Mn}(\mathrm{CO})_{3} \mathrm{~N}_{3}\right]$ with sodium azide, followed by a series of [3+2] azide-alkyne cycloaddition reactions, are reported. The final liberation of the "click" products from the porous material is achieved by $\mathrm{N}$-alkylation with $\mathrm{MeBr}$, regenerating starting $\mathrm{MOF} \mathbf{1} \cdot\left[\mathrm{Mn}(\mathrm{CO})_{3}\left(\mathrm{H}_{2} \mathrm{O}\right)\right] \mathrm{Br}$, and the organic products characterized by NMR spectroscopy and mass spectrometry. Once the dialkyne length exceeds the azide separation, site selectivity is lost, confirming the critical importance of isolated azide moieties for this strategy. We postulate that carefully designed MOFs can act as physical protecting groups to facilitate other site-selective and chemoselective transformations.
\end{abstract}

\section{Introduction}

Metal-organic frameworks (MOFs) are a class of porous materials that are synthesized via a 'building-block' approach from organic links and metal-based nodes. ${ }^{1-2}$ In recent years, they have been intensely studied for their potential application to catalysis, ${ }^{1-8}$ gas storage/separation, ${ }^{9-12}$ biotechnology ${ }^{13-14}$ and microelectronics. ${ }^{15-16}$ A key feature of MOFs is that they can be grown as single crystals, which allows their structures to be elucidated via single-crystal X-ray diffraction (SCXRD). This technique has proved crucial to the development of MOF chemistry by providing molecular-level insight into the nature of gas adsorption, ${ }^{17-19}$ chemical reactions within pore networks, ${ }^{20-25} \mathrm{ca}$ talysis, ${ }^{26-27}$ and the structure of guest molecules. ${ }^{8}$ We recently showed that crystals of the $\mathrm{Mn}(\mathrm{II})$-based MOF 1 (1= $\left[\mathrm{Mn}_{3}(\mathbf{L})_{2}\left(\mathbf{L}^{\prime}\right)\right]$, where $\mathrm{H}_{2} \mathbf{L}=$ bis(4-(4-carboxyphenyl)-1H-3,5dimethylpyrazolyl)methane and $\mathbf{L}^{\prime}$ possesses a non-coordinated bis(3,5-dimethylpyrazol-1-yl)methane moiety) can be employed to structurally characterize the intermediates of a catalytic reaction cycle carried out within the framework pores. ${ }^{20,27}$
A key feature of $\mathbf{1}$ is that it is composed of regularly spaced vacant bis-pyrazolyl groups that are accessible to post-synthetic metalation (PSM) $)^{20,28}$ reactions via ca. 13 Å diameter pores.

Typically, PSM chemistry is employed to enhance the performance characteristics of a given framework; however, we hypothesized that the spatial isolation of reactive metal centers could be employed to carry out chemoselective reactions within MOF pores without the need for a traditional protecting group. To realize this concept, we incorporated an azide functionality into the pores of $\mathbf{1}$ via a two-step process: PSM of $\mathbf{1}$ with $\left[\mathrm{Mn}(\mathrm{CO})_{5} \mathrm{Br}\right]$ followed by halide exchange with sodium azide to afford $1 \cdot\left[\mathrm{Mn}(\mathrm{CO})_{3} \mathrm{~N}_{3}\right]$, which is primed for further reaction. The azide groups of $\mathbf{1} \cdot\left[\mathrm{Mn}(\mathrm{CO})_{3} \mathrm{~N}_{3}\right]$ are located $13 \AA$ apart and thus uniquely poised to selectively carry out an azide-alkyne $[3+2]$ cycloaddition reaction on one of the alkyne moieties of a symmetrical dialkyne (Figure 1). Synthetic approaches towards the preparation of compounds that 

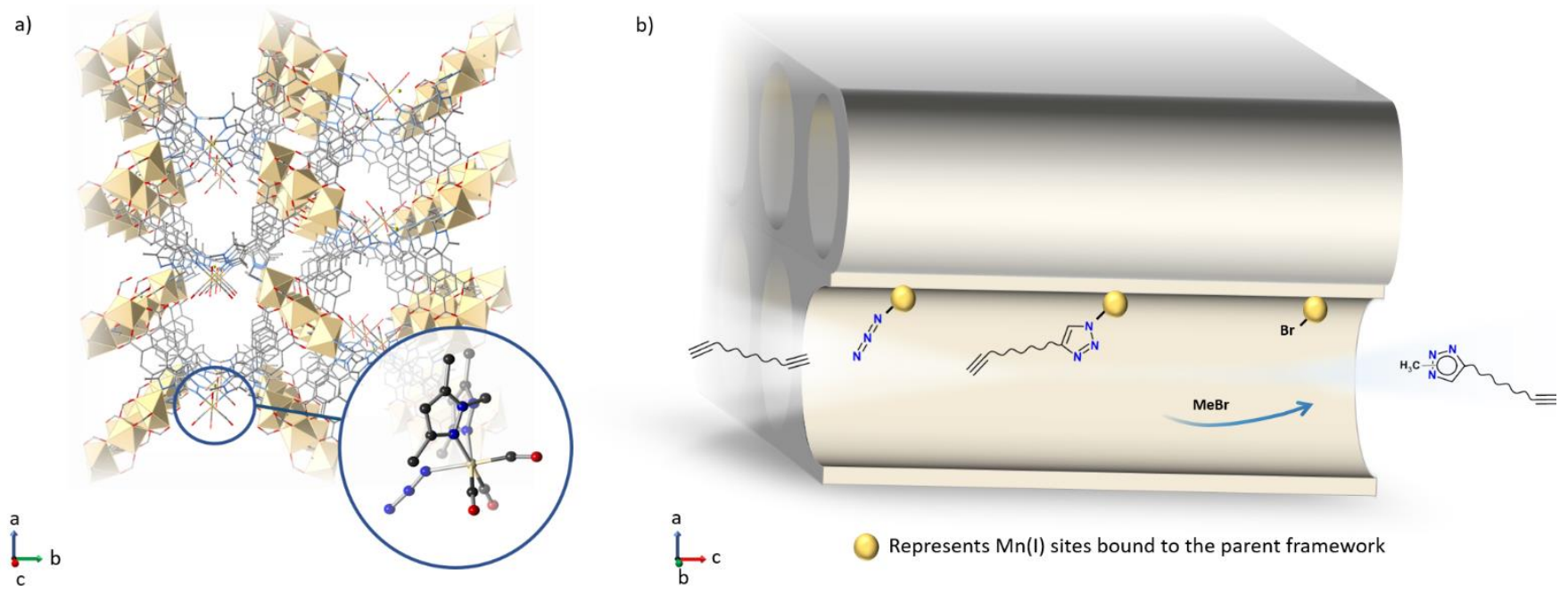

Figure 1. (a) A representation of the spatially isolated azide sites along the 1-D $c$-axis pores of 1 (C, dark grey; N, blue; O, red; Mn, beige; $\mathrm{H}$ atoms omitted for clarity). The insert reveals the coordination chemistry about the PSM added Mn(I) center in the MOF, showing the loaded azide reagent in the axial site. (b) A graphical depiction of the site-isolation strategy using a dialkyne substrate, showing the introduction of the dialkyne, its "click" conversion (the Mn(I) sites are periodically separated by $c a$. $13 \AA$ ), and then liberation by alkylation with $\mathrm{MeBr}$ to produce the desired N-methyl alkynyl triazole.

possess both triazole and alkyne functional groups generally proceed via chemical protection of one alkyne or the addition of the alkyne fragment to a pre-formed halogenated triazole derivative via Sonogashira coupling. ${ }^{29-30}$ Direct synthesis of alkyne-substituted triazoles from the corresponding azide and polyalkyne reagents are less common. Tykwinski et. al., however, reported the preparation of triazoles bearing poly-alkyne substituents from non-symmetric poly-alkynes and benzyl azide. ${ }^{31}$ Other studies have reported the synthesis of 5-alkynyl triazoles from poly-alkynes featuring phenyl $^{32}$ or trimethyl-silyl ${ }^{30}$, ${ }^{33}$ terminal groups. However, direct "click"-type synthesis of triazoles bearing unhindered terminal alkyne substituents have not been reported.

Herein we employ SCXRD to demonstrate that reactive-site isolation in a MOF scaffold facilitates site-selective reactions. Single-crystal to single-crystal (SC-SC) transformations of 1. $\left[\mathrm{Mn}(\mathrm{CO})_{3}\left(\mathrm{H}_{2} \mathrm{O}\right)\right] \mathrm{Br}$ to the corresponding azide species $\mathbf{1} \cdot\left[\mathrm{Mn}(\mathrm{CO})_{3} \mathrm{~N}_{3}\right]$ with sodium azide, followed by a series of $[3+2]$ azide-alkyne cycloaddition reactions, and final liberation of the "click" products from the porous material by N-alkylation with $\mathrm{MeBr}$ to regenerate $\mathbf{1} \cdot\left[\mathrm{Mn}(\mathrm{CO})_{3}\left(\mathrm{H}_{2} \mathrm{O}\right)\right] \mathrm{Br}$, were examined by SCXRD and IR spectroscopy to reveal the postulated reaction cycle. Five alkynes, namely dimethyl-acetylene dicarboxylate (DMAD), ethyl-propiolate (EPOP), 1,7-octadiyne3,6-dione (DA1), 1,9-decadiyne-3,8-dione (DA2), and 1,11-dodecadiyne-3,10-dione (DA3) were investigated to test the site isolation hypothesis. For all alkyne substrates, the reactions yield the desired triazoles, and reveal an unexpected $\mathrm{N} 1$ binding mode of the triazole in the MOF. In particular, we demonstrate the site-selective conversion of dialkynes into alkyne-substituted triazoles when the structure metrics of the dialkyne are smaller than the azide group spacing in the MOF. This study exemplifies how the inherent crystallinity of MOFs can be exploited to gain a fundamental understanding of chemical reactivity within their pores. Additionally, it develops the concept of how the modular approach to MOF synthesis can lead to the precise spatial isolation of reactive sites that are poised to bind substrates $^{34}$ and facilitate site-selective reactions.

\section{Results and Discussion}

\section{Azide "loading" of the MOF}

We previously showed that the functionality of MOF 1 can be tailored via quantitative metalation of the bis-pyrazole moieties lining its pore network. ${ }^{20,27}$ The flexible organic linker allows the MOF structure to respond dynamically to the changing coordination environment of the PSM added metal without compromising the integrity of the single crystals. The post-synthetically introduced reactive sites are uniformly distributed within the MOF (ca. $13 \AA$ apart), and so we envisaged that they may be employed to carry out site-selective chemical transformations (Figure 1). For example, based on collision theory, a homogeneous [3+2] cycloaddition reaction between an inorganic azide and dialkyne would conventionally yield a mixture of triazole products. However, the equivalent reaction employing a derivative of $\mathbf{1}$ bearing site-isolated inorganic azides should selectively yield the alkyne-functionalized triazolate complex, owing to the physical separation of the adjacent azides. Accordingly, to explore the potential of MOFs as reaction vessels for site-selective chemistry, we sought to perform selective [3+2] cycloaddition reactions using an azide-functionalized version of $\mathbf{1}$.

An azide-functionalized derivative of $\mathbf{1}$ was prepared by a sequential metalation and anion-exchange strategy. Initially MOF 1 was treated with $\left[\mathrm{Mn}(\mathrm{CO})_{5} \mathrm{Br}\right]$ in ethanol at 
a)

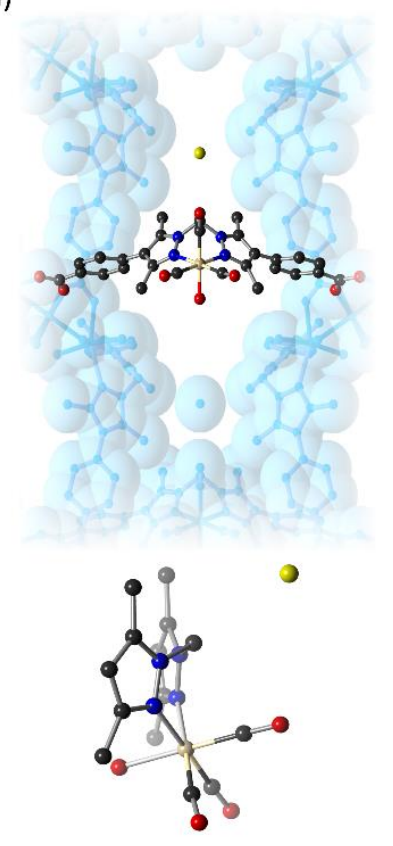

b)
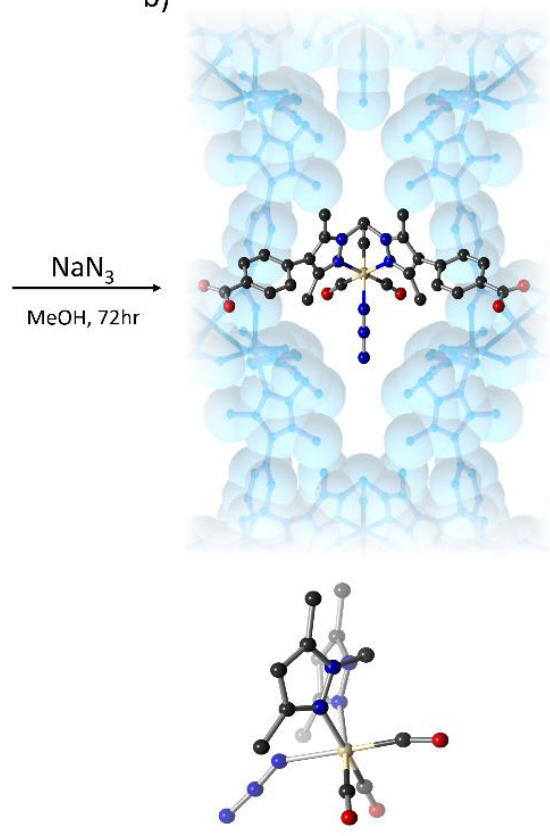

c)

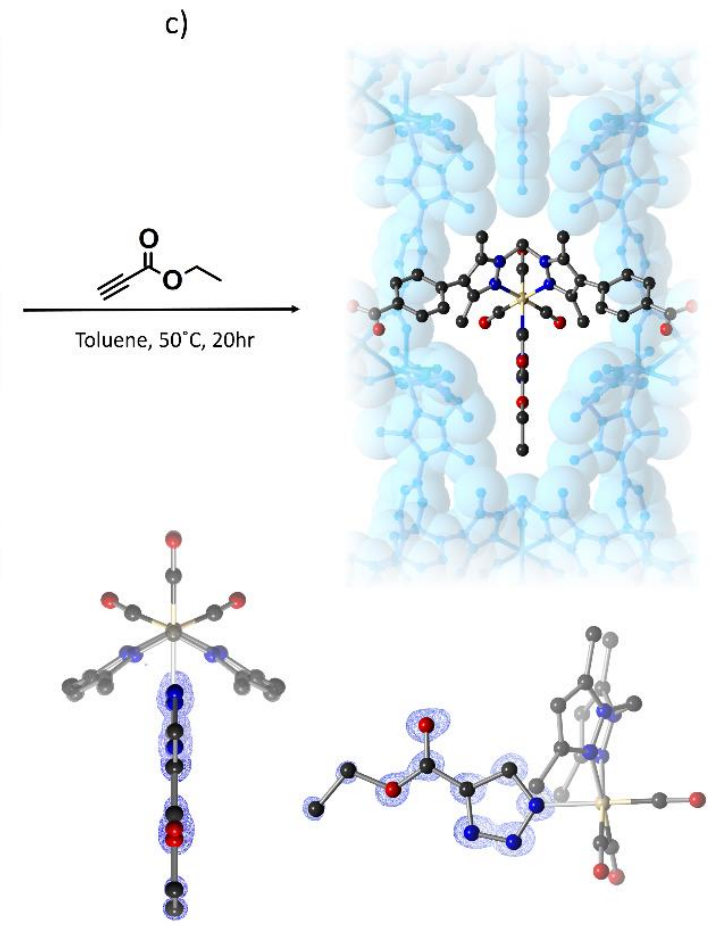

Figure 2. Representations of the metalated N,N-chelation site in the pore space of $\mathbf{1}$ at key steps in the "click" chemistry reaction scheme, with a perspective view of each complex shown below. (a) $\mathbf{1} \cdot\left[\mathrm{Mn}(\mathrm{CO})_{3}\left(\mathrm{H}_{2} \mathrm{O}\right)\right] \mathrm{Br}$, displaying the facial isomer of the $\left[\mathrm{Mn}(\mathrm{CO})_{3}\left(\mathrm{H}_{2} \mathrm{O}\right)\right]$ moiety following post-synthetic metalation, (b) $\mathbf{1} \cdot\left[\mathrm{Mn}(\mathrm{CO})_{3} \mathrm{~N}_{3}\right]$, following facile exchange of $\mathrm{Br}^{-}$for $\mathrm{N}_{3}{ }^{-}$, and (c) $\mathbf{1} \cdot\left[\mathrm{Mn}(\mathrm{CO})_{3}(\mathrm{ET})\right]$ (where ET = ethyl-4-carboxy-1,2,3-triazolate), the triazolate complex following reaction of the azide with ethyl-propiolate, including side and top views of the $\mathrm{F}_{\text {obs }}$ electron density map associated with the triazolate. The parent MOF framework is represented by a translucent, blue van der Waal's surface (C, dark grey; $\mathrm{N}$, blue; $\mathrm{O}$, red; $\mathrm{Mn}$, beige; $\mathrm{Br}$, yellow; $\mathrm{H}$ atoms omitted for clarity).

$50^{\circ} \mathrm{C}$. The crystalline product was characterized by synchrotron SCXRD, which elucidated that the $\mathrm{N}, \mathrm{N}$-chelation site of $\mathbf{1}$ was occupied by a manganese tricarbonyl moiety, fac1. $\left[\mathrm{Mn}(\mathrm{CO})_{3}\left(\mathrm{H}_{2} \mathrm{O}\right)\right] \mathrm{Br}$, with a non-coordinated $\mathrm{Br}^{-}$counterion. Quantitative metalation was confirmed by energy-dispersive Xray (EDX) analysis which yielded an $\mathrm{Mn}: \mathrm{Br}$ ratio of $4: 1$. We also examined 1.[Mn $\left.(\mathrm{CO})_{3}\left(\mathrm{H}_{2} \mathrm{O}\right)\right] \mathrm{Br}$ by IR spectroscopy, which revealed characteristic $\mathrm{C} \equiv \mathrm{O}$ stretches at 1951, 2040 and $1921 \mathrm{~cm}^{-1} \cdot 35-37 \quad$ Additionally, the phase purity of 1. $\left[\mathrm{Mn}(\mathrm{CO})_{3}\left(\mathrm{H}_{2} \mathrm{O}\right)\right] \mathrm{Br}$ was confirmed by PXRD analysis (SI Figure S6.3).

Anion-exchange reactions are well known for metal-halide complexes. Thus, we explored the direct exchange of the noncoordinated bromide with azide to decorate the pores of the MOF with azide moieties. Crystals of $\mathbf{1} \cdot\left[\mathrm{Mn}(\mathrm{CO})_{3}\left(\mathrm{H}_{2} \mathrm{O}\right)\right] \mathrm{Br}$ were soaked in a methanol solution of sodium azide $\left(\mathrm{NaN}_{3}\right)$ for three days to yield $\mathbf{1} \cdot\left[\mathrm{Mn}(\mathrm{CO})_{3} \mathrm{~N}_{3}\right]$. The IR spectrum of 1. $\left[\mathrm{Mn}(\mathrm{CO})_{3} \mathrm{~N}_{3}\right]$ revealed a strong IR stretch at $2070 \mathrm{~cm}^{-1}$ that is typical of a metal-coordinated azide; ${ }^{35,37-39}$ furthermore, the expected $v(\mathrm{C} \equiv \mathrm{O})$ bands were observed at 2025, 1952, and 1903 $\mathrm{cm}^{-1}$. The elemental composition of $\mathbf{1} \cdot\left[\mathrm{Mn}(\mathrm{CO})_{3} \mathrm{~N}_{3}\right]$ was assessed by EDX analysis to provide insight into the extent of $\mathrm{Br}^{-}$ substitution. Close inspection of the data showed that subsequent to the anion exchange protocol the $\mathrm{Mn}: \mathrm{Br}$ ratio decreased from 4:1 to 4:0.07. Throughout the anion-exchange process the MOF retained its crystallinity allowing us to collect SCXRD data. These experiments elucidated the presence of an azide anion bound to the axial site of the octahedral $\mathrm{Mn}(\mathrm{I})$ complex and retention of the facially coordinated $\mathrm{C} \equiv \mathrm{O}$ ligands. The crystal structure of $\mathbf{1} \cdot\left[\mathrm{Mn}(\mathrm{CO})_{3} \mathrm{~N}_{3}\right]$ obtained using synchrotron radiation also confirmed that the azide anions are site-isolated (ca. $13 \AA$ apart), well ordered and accessible to guest molecules rendering this MOF an ideal candidate for site-selective "click" chemistry.

\section{"Click" chemistry within the MOF pores}

The azide functional group is known to participate in the $[3+2]$ cycloaddition reaction with alkyne moieties to form a triazole (in the case of an organic azide) or triazolate salt (for an inorganic azide complex). ${ }^{40-42}$ This prototypical "click" reaction is applied in numerous fields of chemistry, such as dendrimer synthesis, ${ }^{43-44}$ preparation of pharmaceuticals,${ }^{45-48}$ postsynthetic modification of MOFs, ${ }^{49-51}$ and extensively in polymer science. ${ }^{52-53}$ The Cu-catalyzed [3+2] cycloaddition reaction between organic azides and alkynes has been studied in various MOF frameworks ${ }^{54-55}$ and zeolites. ${ }^{56}$ However, in $\mathbf{1} \cdot\left[\mathrm{Mn}(\mathrm{CO})_{3} \mathrm{~N}_{3}\right]$ the azide source is inorganic and, although such transformations are colloquially termed "click" reactions, the reaction described herein is formally a Huisgen cycloaddition process. Importantly, it is expected that the reaction between $1 \cdot\left[\mathrm{Mn}(\mathrm{CO})_{3} \mathrm{~N}_{3}\right]$ and an alkyne will yield a product in which the triazolate is coordinated to the structurally isolated Mn sites. ${ }^{38}$ Thus, if a dialkyne is employed the physical separation between the triazolate complex and adjacent azide moiety, imposed by 
the host framework, would prevent the remaining alkyne from participating in a secondary "click" reaction (Figure 1). Furthermore, the $\mathrm{N}$-alkyl organic triazole can be easily liberated via reaction with an alkyl halide. This chemistry facilitates a novel synthesis strategy for alkyne-functionalized triazoles via step-wise inorganic "click" chemistry and $\mathrm{N}$-alkylation.

We exposed single crystals of $\mathbf{1} \cdot\left[\mathrm{Mn}(\mathrm{CO})_{3} \mathrm{~N}_{3}\right]$ to two electron-deficient alkynes, dimethyl-acetylene dicarboxylate (DMAD) and ethyl-propiolate (EPOP) to afford $\mathbf{1} \cdot\left[\mathrm{Mn}(\mathrm{CO})_{3}(\mathrm{DMT})\right]$ and $\mathbf{1} \cdot\left[\mathrm{Mn}(\mathrm{CO})_{3}(\mathrm{ET})\right], \quad$ respectively (where DMT = dimethyl 4,5-dicarboxy-1,2,3-triazolate and ET = ethyl 4-carboxy-1,2,3-triazolate). Each reaction was performed at $50^{\circ} \mathrm{C}$ in toluene to promote formation of the corresponding triazolate complex and after $24 \mathrm{~h}$ the respective samples were examined by FTIR spectroscopy. In both spectra the characteristic azide asymmetric stretch at $2070 \mathrm{~cm}^{-1}$ of $\mathbf{1} \cdot\left[\mathrm{Mn}(\mathrm{CO})_{3} \mathrm{~N}_{3}\right]$ was absent, indicating that quantitative conversion of the azide had occurred (Figure $3 \mathrm{a}$ and SI Figure S7.1). Furthermore, the simultaneous growth of a methyl or ethyl ester carbonyl stretch at 1716 and $1711 \mathrm{~cm}^{-1}$ respectively, was observed, supporting the presence of a coordinated triazolate moiety. ${ }^{57}$ PXRD experiments performed on the MOF crystals after the "click" reactions indicate that the bulk material retains a high degree of crystallinity (Figure 3b, data shown for the EPOP cycle).

Remarkably, subsequent to successive anion exchange and 'click' reactions the crystals of $\mathbf{1} \cdot\left[\mathrm{Mn}(\mathrm{CO})_{3}(\mathrm{DMT})\right]$ and $\mathbf{1} \cdot\left[\mathrm{Mn}(\mathrm{CO})_{3}(\mathrm{ET})\right]$ remained suitable for SCXRD. Structure solution and data refinement revealed the presence of an $\mathrm{N}(1)$ bound triazolate product in both $\mathbf{1} \cdot\left[\mathrm{Mn}(\mathrm{CO})_{3}(\mathrm{ET})\right]$ (Figure 2c) and 1·[Mn(CO) $\left.)_{3}(\mathrm{DMT})\right]$ (SI Figure S5.2.3). The structure determinations were further supported by a close match of the structural model to the $\mathrm{F}_{\mathrm{obs}}$ electron density maps (Figure $2 \mathrm{c}$ ). In both instances, the triazolate resides on the mirror plane bisecting the $\mathrm{Mn}(\mathrm{I})$ complex and is coordinated to the axial site formerly occupied by azide in $\mathbf{1} \cdot\left[\mathrm{Mn}(\mathrm{CO})_{3} \mathrm{~N}_{3}\right]$. Close examination of the data indicates preferential formation of an $\mathrm{N}(1)$ bound complex in 1· $\left[\mathrm{Mn}(\mathrm{CO})_{3}(\mathrm{DMT})\right]$ (SI Figure S5.2.3). The single ethyl ester substituent in $\mathbf{1} \cdot\left[\mathrm{Mn}(\mathrm{CO})_{3}(\mathrm{ET})\right]$ is appended such that it projects into the MOF pore and, by assigning the largest electron density peaks in the triazole ring system as nitrogen atoms, we also refined the triazolate complex as an $\mathrm{N}(1)$ bound isomer consistent with that observed in $\mathbf{1} \cdot\left[\mathrm{Mn}(\mathrm{CO})_{3}(\mathrm{DMT})\right]$.

\section{Unusual "in MOF" triazolate coordination}

$\mathrm{N}(1)$-bound octahedral triazolate complexes, such as $\mathbf{1} \cdot\left[\mathrm{Mn}(\mathrm{CO})_{3}(\mathrm{DMT})\right]$ and $\mathbf{1} \cdot\left[\mathrm{Mn}(\mathrm{CO})_{3}(\mathrm{ET})\right]$, are rare, ${ }^{38,}, 57-59$ since steric effects in octahedral complexes usually favor the rearrangement of the complex to form the $\mathrm{N}(2)$-bound isomer. ${ }^{35}$, 39 It is evident from the crystal structures that close contacts between the coordinated triazolate and adjacent features of the MOF pore would be substantially increased if the triazolate were to bind via the $\mathrm{N}(2)$ nitrogen. To confirm that the MOF environment, rather than the primary coordination environment, are responsible for this behavior, we synthesized the molecular counterpart, [Mn(bis(3,5-dimethyl-pyrazolyl)methane $)(\mathrm{CO})_{3}($ dimethyl 4,5-carboxy-1,2,3-triazolate)] $\left(\left[\mathrm{Mn}(\mathrm{bpm})(\mathrm{CO})_{3}(\mathrm{DMT})\right]\right.$, where bpm $=$ bis(3,5-dimethyl-pyrazolyl)methane). SCXRD studies revealed an N(2)-bound triazolate coordinated to a $f a c-\mathrm{Mn}(\mathrm{I})$ tricarbonyl complex (SI Figure S5.1.1). Evidently, the MOF environment enforces new steric demands on the triazolate, favoring coordination motifs that reduce steric interactions between the host framework and triazolate. Density functional theory calculations support this hypothesis. Comparison of the calculated energies of the N(1)and $\mathrm{N}(2)$-bound complexes in $\mathbf{1} \cdot\left[\mathrm{Mn}(\mathrm{CO})_{3}(\mathrm{DMT})\right]$ and molecular species shows that the framework stabilizes the $\mathrm{N}(1)$ bound isomer by $11 \mathrm{~kJ} / \mathrm{mol}$ with respect to the $\mathrm{N}(2)$-bound isomer. Furthermore, significant steric interactions between the host

framework
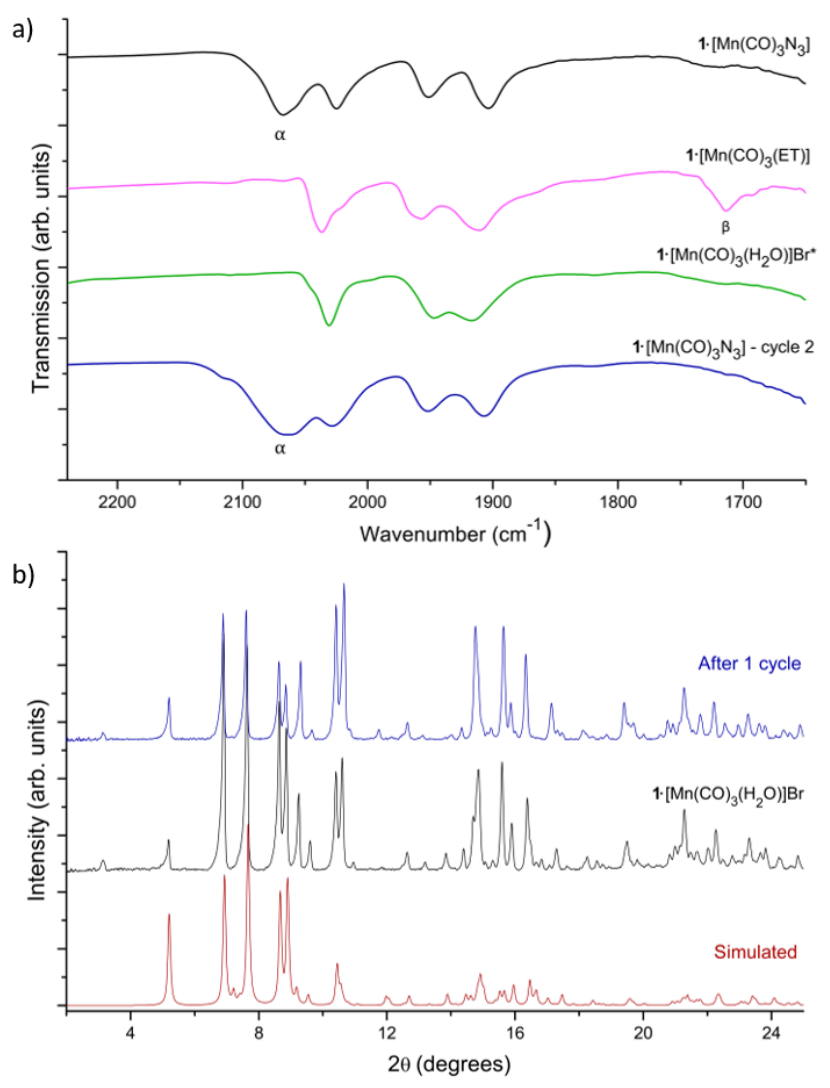

Figure 3. (a) IR spectra of $\mathbf{1} \cdot\left[\mathrm{Mn}(\mathrm{CO})_{3} \mathrm{~N}_{3}\right]$ and the "click"chemistry product $1 \cdot\left[\mathrm{Mn}(\mathrm{CO})_{3}(\mathrm{ET})\right]$, confirming loss of the $\mathrm{N}_{3}$ stretch $\left(2070 \mathrm{~cm}^{-1}\right.$, indicated by $\left.\alpha\right)$ and formation of the ethyl ester carbonyl (stretch near $1700 \mathrm{~cm}^{-1}$, indicated by $\beta$ ), which supports the formation of the observed triazolate product. The alkylation of the triazolate is observed as a decrease in the ester stretch in $\mathbf{1} \cdot\left[\mathrm{Mn}(\mathrm{CO})_{3}(\mathrm{ET})\right]$, and the resulting bromide complex readily undergoes azide exchange to regenerate $1 \cdot\left[\mathrm{Mn}(\mathrm{CO}){ }_{3} \mathrm{~N}_{3}\right]$. (b) PXRD data obtained from the material after one click cycle using EPOP closely matches the starting material, $\mathbf{1} \cdot\left[\mathrm{Mn}(\mathrm{CO})_{3}\left(\mathrm{H}_{2} \mathrm{O}\right)\right] \mathrm{Br}$ and the simulated pattern, indicating that the MOF retains crystallinity throughout the cycle.

and the methyl substituents on the DMT ligand along the pathway that converts the moiety from an $\mathrm{N}(1)$ - to the $\mathrm{N}(2)$-bound complex results in a substantial calculated energy barrier for this process of around $170 \mathrm{~kJ} / \mathrm{mol}$. This indicates that it is highly unlikely for the N(1)-bound complex that is initially formed in the "click" reaction ${ }^{38}$ to transform into the $\mathrm{N}(2)$ bound complex (see the Supporting Information for a detailed description of the computational procedures and results).

\section{Triazole release from the MOF platform}

For the MOF to act as a functional host for "click" chemistry, the organic product must be liberated and the original framework 'vessel' re-generated in suitable condition to perform further reaction cycles. Due to the strong metal-triazolate 
bond, simple anion exchange with sodium azide is not sufficient to release the triazolate. Fortunately, this issue is overcome by reacting the MOF-bound triazolate complex with $\mathrm{MeBr}$ 57, 60-61 to release the corresponding $\mathrm{N}$-alkylated triazole and regenerate the original host framework, $1 \cdot\left[\mathrm{Mn}(\mathrm{CO})_{3}\left(\mathrm{H}_{2} \mathrm{O}\right)\right] \mathrm{Br}$. We note that this process also occurs via a SC-SC transition. To monitor the reaction we employed NMR spectroscopy and EDX analysis to assess the formation of the $\mathrm{N}$-alkylated triazole and the MOF-bound halide complex, respectively. Alkylation was performed by placing crystals of $\mathbf{1} \cdot\left[\mathrm{Mn}(\mathrm{CO})_{3}(\mathrm{DMT})\right]$ in $\mathrm{CDCl}_{3}$ and heating the mixture at $50^{\circ} \mathrm{C}$ overnight in the presence of excess $\mathrm{MeBr}$. Following removal of the MOF crystals, the $\mathrm{CDCl}_{3}$ solution was analyzed via ${ }^{1} \mathrm{H}-\mathrm{NMR}$ spectroscopy and found to contain dimethyl N1-methyl-4,5-dicarboxy-1,2,3-triazole. The position of the methyl group on the triazole ring was confirmed by the presence of two separate methyl ester signals in the ${ }^{1} \mathrm{H}$ NMR spectrum, indicating alkylation at N(1). ${ }^{57}$ Notably, PXRD patterns obtained after a full "click" chemistry cycle demonstrated a high degree of crystallinity (Figure 3b), as evidenced by the excellent agreement between the patterns of $\mathbf{1} \cdot\left[\mathrm{Mn}(\mathrm{CO})_{3}\left(\mathrm{H}_{2} \mathrm{O}\right)\right] \mathrm{Br}$ and $\mathbf{1} \cdot\left[\mathrm{Mn}(\mathrm{CO})_{3}\left(\mathrm{H}_{2} \mathrm{O}\right)\right] \mathrm{Br} *$ (* indicates a MOF that has completed one reaction cycle). Quantitative regeneration of the $\mathrm{Mn}(\mathrm{I})$ bromide complex is supported by EDX experiments, which indicate a 4:1 $\mathrm{Mn}: \mathrm{Br}$ ratio (SI Table $\mathrm{S} 1$ ) while the IR spectrum of $\mathbf{1} \cdot\left[\mathrm{Mn}(\mathrm{CO})_{3}\left(\mathrm{H}_{2} \mathrm{O}\right)\right] \mathrm{Br}^{*}$ shows analogous $v(\mathrm{C} \equiv \mathrm{O})$ bands to $\mathbf{1} \cdot\left[\mathrm{Mn}(\mathrm{CO})_{3}\left(\mathrm{H}_{2} \mathrm{O}\right)\right] \mathrm{Br}$. Furthermore, reaction of $\mathbf{1} \cdot\left[\mathrm{Mn}(\mathrm{CO})_{3}(\mathrm{ET})\right]$ with $\mathrm{MeBr}$ successfully released ethyl $\mathrm{N}$-methyl-4-carboxy-1,2,3-triazole to regenerate the original framework. ${ }^{1} \mathrm{H}$ NMR spectroscopy indicated that the liberated product was a mixture of two $\mathrm{N}$-alkylated isomers in a $5: 3$ ratio. In addition, complete loss of the ester $v(\mathrm{C}=\mathrm{O})$ band in the IR spectrum supports the quantitative expulsion of the organic triazole from the MOF (Figure 3a). This data supports the successful use of $\mathbf{1}$ as a platform for the complete "click" chemistry cycle.

Buoyed by these results, we subjected the material to a second azide exchange cycle and observed a prominent azide stretch in the IR spectrum, consistent with that observed for $\mathbf{1} \cdot\left[\mathrm{Mn}(\mathrm{CO})_{3} \mathrm{~N}_{3}\right]$ (Figure 3a). These results confirm that the material could serve as a platform for "click" chemistry over multiple cycles.

\section{Selective "click" chemistry with dialkynes}

Having established the viability of $\mathbf{1}$ as a host for stoichiometric "click" conversions, we turned our attention to carrying out site-selective functionalization on a dialkyne substrate to directly produce the corresponding alkyne-functionalized $\mathrm{N}$-alkylated triazole. We selected a series of terminal dialkynes DA1, DA2 and DA3 with lengths of $10.7,13.1$ and $15.6 \AA$, respectively. Since the azide separation in $\mathbf{1} \cdot \mathrm{N}_{3}$ is $13.0 \AA$, we anticipated that the shortest dialkyne would undergo site-selective "click" chemistry while the longest species would produce a mixture of bis- and mono-triazole products as its length exceeds the azide separation.

We selected the symmetric dialkyne substrates since the well-separated and unhindered terminal alkyne sites pose a challenging profile for selective triazole formation. The inclusion of carbonyl groups adjacent to the alkyne activate them toward "click" chemistry, as seen for DMAD and EPOP, by withdrawing electron density from the triple bond. The "click" reactions were performed in toluene at $50^{\circ} \mathrm{C}$ and monitored via IR spectroscopy which showed a gradual loss of the asymmetric $\mathrm{N}_{3}^{-}$stretch at $2070 \mathrm{~cm}^{-1}$. PXRD analysis after the reaction was complete confirmed that the MOF retained crystallinity (SI Figure S6.3-6.5), while the IR spectrum displayed a $\mathrm{C}=\mathrm{O}$ stretch at $1690 \mathrm{~cm}^{-1}$ consistent with presence of the ketone functionality.

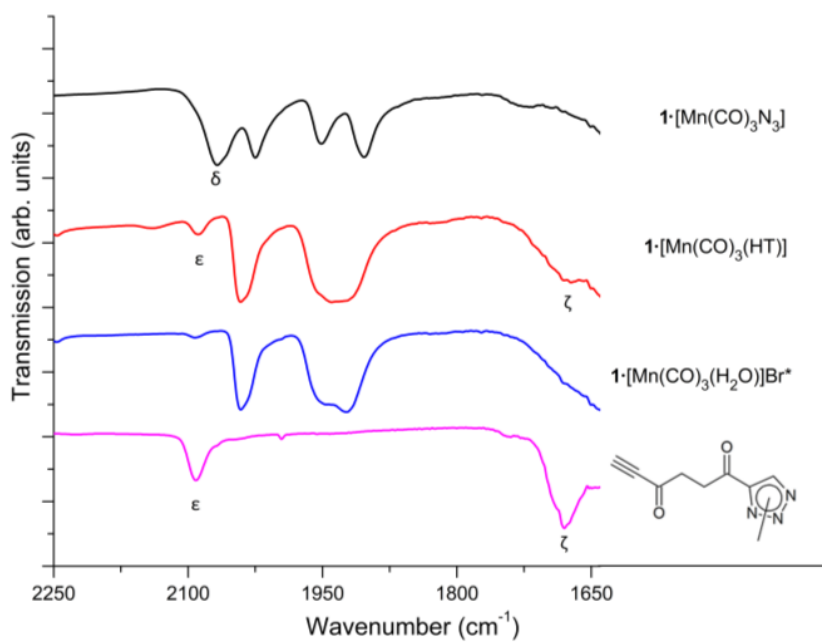

Figure 4. (a) IR spectra of $\mathrm{Mn}(\mathrm{I})$ metalated forms of 1 displaying characteristic $\mathrm{CO}$ stretches, which are retained throughout the "click" chemistry cycle. The progression of the anion exchange, "click" reaction and $\mathrm{N}$-alkylation can be monitored by the appearance and loss of the azide stretch at $2070 \mathrm{~cm}^{-1}(\delta)$ and concomitant formation of the alkyne and ester stretches at 2090 and $1680 \mathrm{~cm}^{-1}$ respectively ( $\varepsilon$ and $\zeta$, respectively). The liberated triazole product displays the same spectroscopic features.

The MOF crystals of $\mathbf{1} \cdot\left[\mathrm{Mn}(\mathrm{CO})_{3}(4-\right.$ hex-5' -ynl-1',4'-dione1,2,3-triazolate $)]\left(\mathbf{1} \cdot\left[\mathrm{Mn}(\mathrm{CO})_{3}(\mathrm{HT})\right]\right)$ were found to be suitable for SCXRD studies. Refinement of the structure revealed the presence of a five-membered ring coordinated to the $\mathrm{Mn}(\mathrm{I})$ site, which was assigned as an N(1)-bound triazolate. Furthermore, the alkyne functionalized chain can be discerned in the electron density map, bound to $\mathrm{C} 4$ of the triazole. Refinement without crystallographic restraints was not possible, but an energy-minimized organic moiety could be modelled in this site and provides a reasonable match to the $\mathrm{F}_{\mathrm{obs}}$ electron density map (SI Figure S5.3.5). In addition, the IR spectrum of $\left(\mathbf{1} \cdot\left[\mathrm{Mn}(\mathrm{CO})_{3}(\mathrm{HT})\right]\right)$ showed a band at $2090 \mathrm{~cm}^{-1}$, characteristic of an alkyne $\mathrm{C} \equiv \mathrm{C}$ stretch along with concomitant loss of the azide band at $2070 \mathrm{~cm}^{-1}$ (Figure 4). Consistent with our hypothesis, this evidence confirms that the shortest dialkyne, DA1, produces the site-selective 'click', product, 4-hex-5'-ynl1',4'-dione-1,2,3-triazolate. 
(a) Site-selective Reaction (DA1)
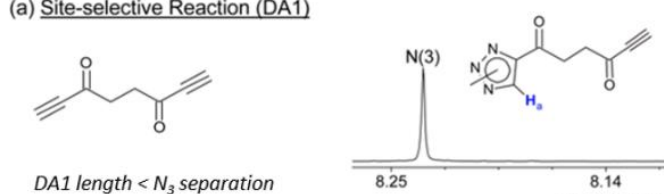

Chemical shift (ppm)

(b) Non-selective Reactions (DA2 and DA3)

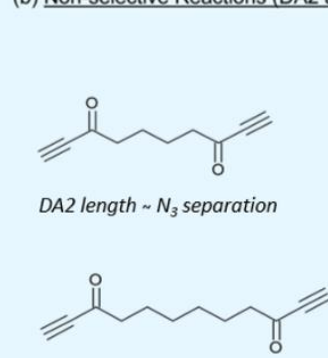

DA3 length $>N_{3}$ separation

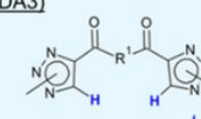

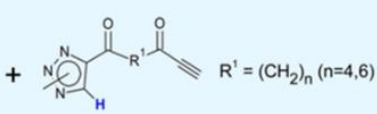

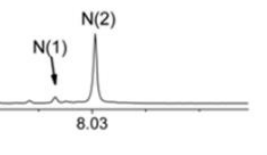

(c)

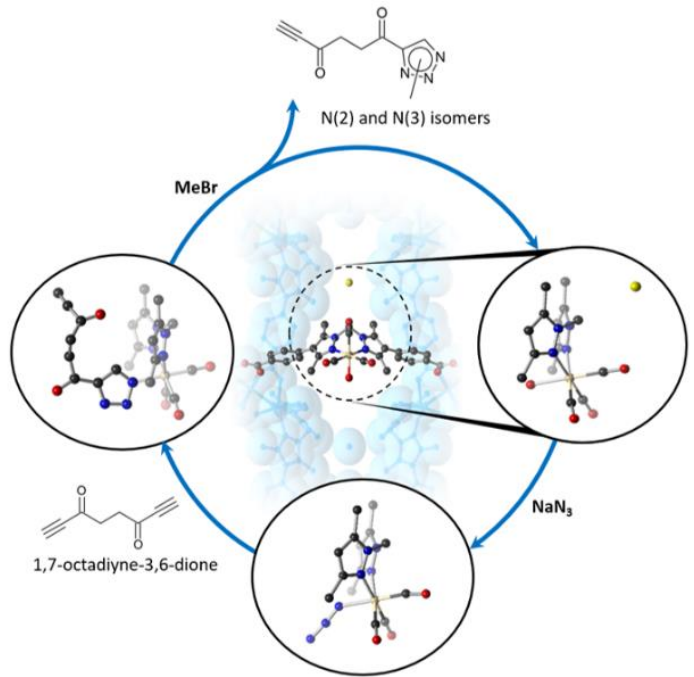

Figure 5. (a) The shortest dialkyne, DA1, undergoes site-selective “click" chemistry to yield N-methyl 4-hex-5'-ynl-1',4'-dione-1,2,3triazole $\left(\mathrm{N}(2)\right.$ and $\mathrm{N}(3)$ major isomers), as indicated by consideration of the $\mathrm{CH}$ triazole region of the ${ }^{1} \mathrm{H}$ NMR spectrum, which shows two prominent triazole $\mathrm{CH}$ signals (note: the $\mathrm{N}$ (1)-methyl isomer is also present in small quantity; see SI). (b) Extension of the dialkyne substrate results in a mixture of bis- and mono- "click" products, resulting in multiple triazole CH peaks in the ${ }^{1} \mathrm{H}$ NMR spectrum; the lower intensity signals are highlighted by a blue arrow. The number of triazole $\mathrm{CH}$ signals increases with the dialkyne length, indicating a greater proportion of bis-triazole products and loss of site-selectivity. (c) Site-selective "click" chemistry cycle using DA1 proceeding from $\mathbf{1} \cdot\left[\mathrm{Mn}(\mathrm{CO})_{3}\left(\mathrm{H}_{2} \mathrm{O}\right)\right] \mathrm{Br}$ to $\mathbf{1} \cdot\left[\mathrm{Mn}(\mathrm{CO})_{3} \mathrm{~N}_{3}\right]$, formation of the "click" triazolate complex and regeneration of the starting material $\mathbf{1} \cdot\left[\mathrm{Mn}(\mathrm{CO})_{3}\left(\mathrm{H}_{2} \mathrm{O}\right)\right] \mathrm{Br}$ via alkylation with $\mathrm{MeBr}$.

Each of the DA1-, DA2- and DA3-derived triazolate complexes were reacted with $\mathrm{MeBr}$ to yield $\mathbf{1} \cdot\left[\mathrm{Mn}(\mathrm{CO})_{3}\left(\mathrm{H}_{2} \mathrm{O}\right)\right] \mathrm{Br}$ and the respective $\mathrm{N}$-alkylated triazole product using the alkylation protocol discussed earlier. In all cases the reaction was accompanied by a color change in the crystals from red to a yellow-orange color consistent with re-formation of $\mathbf{1} \cdot\left[\mathrm{Mn}(\mathrm{CO})_{3}\left(\mathrm{H}_{2} \mathrm{O}\right)\right] \mathrm{Br}$. IR spectroscopy of each MOF sample showed the characteristic $\mathrm{C} \equiv \mathrm{O}$ stretches, confirming the presence of the tricarbonyl moiety and the PXRD patterns obtained after the full "click" chemistry cycle closely matched that of the original framework $1 \cdot\left[\mathrm{Mn}(\mathrm{CO})_{3}\left(\mathrm{H}_{2} \mathrm{O}\right)\right] \mathrm{Br}$ (SI Figure S6.3$6.5)$. We characterized the respective triazole products by $1 \mathrm{D}$ and 2D NMR experiments and high-resolution mass spectrometry. The NMR analysis of the product obtained from the shortest dialkyne, 1,7-octadiyne-3,8-dione (DA1), confirmed the selective formation of the alkyne functionalized triazole as a mixture of $\mathrm{N}(3)$ and $\mathrm{N}(2)$-methyl isomers in a 1:0.8 ratio (a trace of the N(1)-methyl isomer was also observed) (Figure 5a). The alkyne moiety was observed as a singlet in the ${ }^{1} \mathrm{H}$ NMR (3.27 ppm and $3.32 \mathrm{ppm}$ for the $\mathrm{N}(2)$ and $\mathrm{N}(3)$ isomers, respectively) and further supported by the IR spectroscopy of the oily product, which displays the characteristic $\mathrm{CH}$ stretch at $3249 \mathrm{~cm}^{-1}$ and $\mathrm{C} \equiv \mathrm{C}$ stretch at $2091 \mathrm{~cm}^{-1}$. High-resolution mass spectrometry clearly identified the $[\mathrm{M}+\mathrm{H}]^{+}$ion at $\mathrm{m} / z, 192.0967$ with only traces of the bis-triazole product observed (SI Figure S4.1). The combination of NMR and IR spectroscopy, and mass spectrometry overwhelmingly supports the successful site-selective "click" reaction to give the desired alkyne-functionalized triazole product.

As anticipated the NMR and mass spectrometry data reveal a direct relationship between the length of the dialkyne, the azide separation and selectivity obtained. Both longer dialkyne substrates, 1,9-decadiyne-3,8-dione (length $13.1 \AA \approx \mathrm{N}_{3}$ separa- tion) and 1,11-dodecadiyne-3,10-dione (length $15.6 \AA$ > $\mathrm{N}_{3}$ separation) gave rise to a greater proportion of bis-triazole product (Figure 5b), with the longest dialkyne producing at least 8 detectable triazole proton environments. These results confirm that the spatial isolation of the azide moieties achieved in $\mathbf{1} \cdot\left[\mathrm{Mn}(\mathrm{CO})_{3} \mathrm{~N}_{3}\right]$ is integral to the site-selective " click' -chemistry strategy, since the selectivity is compromised once the dialkyne length approaches that of the azide separation. In all cases, PXRD analysis confirmed the parent framework is preserved throughout the "click'" chemistry cycle.

\section{Conclusion}

Herein we have demonstrated that the crystalline structure of MOFs can facilitate the angstrom-scale ordering of reactive azide sites to yield a reactive 'vessel' that is poised to perform site-selective "click" chemistry. The high degree of crystallinity of the MOF framework allowed us to precisely characterize the precursor azide sites and "click" chemistry triazolate products using SCXRD, providing insight into the effect of the confining pore environment and isolated reactive sites on chemical processes within MOFs. By way of example we performed site-selective "click" chemistry reaction cycles using a series of dialkynes of different structure metrics. These experiments clearly showed that the degree of site selectivity observed was dependent on the length of the dialkyne relative to the distance between the azide moieties. We anticipate that the scope for employing MOFs as site-selective reaction vessels is vast, given their bespoke design and chemical mutability. Indeed, this chemistry could be extended by precisely positioning guest molecules within the framework via specific dynamic covalent, dative, or H-bonding interactions to facilitate highly efficient chemoselective reactions. To this end, the MOF crystal could be considered to function as a novel solid-state protecting group and, accordingly, this strategy may be broadened to include a 
wide variety of site-selective and chemoselective transformations that are not easily carried out using a traditional protecting-group strategy.

\section{Experimental}

\section{Materials and Methods}

Unless otherwise stated, all preparations of the organic compounds were performed under an Ar atmosphere using standard Schlenk techniques with dried and degassed solvents. All MOF synthesis reactions were carried out in air. $\mathrm{H}_{2} \mathbf{L}$ (bis(4(4-carboxyphenyl)-1H-3,5-dimethylpyrazolyl)methane), bis(3,5-dimethylpyrazolyl)methane (bpm) and 1,9-decadiyne3,8-dione (DA2) were synthesized as previously reported. ${ }^{62}{ }^{63}$ ${ }^{64}$ All reagents were obtained from commercial vendors and used without further purification. NMR spectra were recorded on Varian Gemini 500 or $600 \mathrm{MHz}$ spectrometers at $23^{\circ} \mathrm{C}$ using a $5 \mathrm{~mm}$ probe. Energy-dispersive X-ray spectroscopy (EDX) was performed with a Philips XL30 field emission scanning electron microscope. Infrared (IR) spectra were collected on a Perkin-Elmer Spectrum Two, with the sample distributed between two $\mathrm{NaCl}$ disks in Nujol. Electrospray ionization (ESI) high-resolution mass spectra (HR-MS) were recorded on QTOF mass spectrometer (Agilent 6230). For details regarding the preparation of the dialkynes DA1 and DA3, and the molecular complex $\left[\mathrm{Mn}(\mathrm{bpm})(\mathrm{CO})_{3}(\mathrm{DMT})\right]$, please see the Supplementary Information.

\section{Single Crystal and Powder X-ray Diffraction Data}

Single crystals were mounted in paratone- $\mathrm{N}$ oil on a nylon loop. Single-crystal X-ray data for $\mathbf{1} \cdot\left[\mathrm{Mn}(\mathrm{CO})_{3}\left(\mathrm{H}_{2} \mathrm{O}\right)\right] \mathrm{Br}$, $\mathbf{1} \cdot\left[\mathrm{Mn}(\mathrm{CO})_{3} \mathrm{~N}_{3}\right], \mathbf{1} \cdot\left[\mathrm{Mn}(\mathrm{CO})_{3}(\mathrm{ET})\right], \mathbf{1} \cdot\left[\mathrm{Mn}(\mathrm{CO})_{3}(\mathrm{DMT})\right]$ and $\mathbf{1} \cdot\left[\mathrm{Mn}(\mathrm{CO})_{3}(\mathrm{OT})\right]$ were collected at $100 \mathrm{~K}$ on the MX1 or MX2 beamlines of the Australia Synchrotron using the BluIce software interface, ${ }^{65} \lambda=0.7108 \AA$ A. Single crystal X-ray data for, $\left[\mathrm{Mn}(\mathrm{bpm})(\mathrm{CO})_{3} \mathrm{Br}\right]$ and $\left[\mathrm{Mn}(\mathrm{bpm})(\mathrm{CO})_{3}(\mathrm{DMT})\right]$ were collected at $150(2) \mathrm{K}$ on an Oxford $\mathrm{X}$-Calibur single crystal diffractometer $(\lambda=0.71073 \AA)$. $N_{\text {tot }}$ reflections were merged to $N$ unique $\left(R_{\text {int }}\right.$ quoted) after a multi-scan absorption correction (proprietary software) and used in the full matrix least-squares refinements on $F 2$. Unless otherwise stated in the additional refinement details, anisotropic displacement parameter forms were refined for the non-hydrogen atoms; hydrogen atoms were treated with a riding model [weights: $\left(\sigma 2\left(F_{\mathrm{O}}\right)^{2}+(a P)^{2}+(b P)\right)^{-1}$; $\left.P=\left(F \mathrm{O}^{2}+2 F \mathrm{c}^{2}\right) / 3\right]$. Neutral atom complex scattering factors were used; computation used the SHELXL2014 program. $^{66}$ Pertinent results are given in the manuscript, while views of the asymmetric units, additional refinement details, and X-ray experimental and refinement data (Table S3-4) are given in the Supporting Information. Full details of the structure determinations have been deposited with the Cambridge Crystallographic Data Centre as CCDC \#s 1826673-1826679 (see Table S3-4 for specific deposit numbers). Copies of this information may be obtained free of charge from The Director, CCDC, 12 Union Street, Cambridge CB2 1EZ, U.K. (fax, +44-1223-336-033; email, deposit@ccdc.cam.ac.uk).

Powder X-ray diffraction data were collected on a Bruker Advance D8 diffractometer equipped with a capillary stage using $\mathrm{Cu} \mathrm{K} \alpha$ radiation $(\lambda=1.5418 \AA$ ). Simulated powder X-ray diffraction (PXRD) patterns were produced from the single crystal data using Mercury 3.3.

\section{Synthetic Procedures}

$\mathbf{1} \cdot\left[\mathbf{M n}(\mathbf{C O})_{3}\left(\mathbf{H}_{2} \mathbf{O}\right)\right] \mathbf{B r}$. Single crystals of $\mathbf{1}(30 \mathrm{mg})$ were washed with ethanol $(5 \times 10 \mathrm{ml})$ with 30 minutes between each wash. The crystals of 1 were transferred to a $20 \mathrm{ml}$ scintillation vial containing ethanol $(15 \mathrm{ml})$ and excess $\left[\mathrm{Mn}(\mathrm{CO})_{5} \mathrm{Br}\right](30$ $\mathrm{mg})$. The mixture was heated at $50^{\circ} \mathrm{C}$ for $48 \mathrm{~h}$ and the resulting yellow crystals were washed with fresh ethanol $(5 \times 10 \mathrm{ml})$ to give $1 \cdot\left[\mathrm{Mn}(\mathrm{CO})_{3}\left(\mathrm{H}_{2} \mathrm{O}\right)\right] \mathrm{Br}$ as yellow single crystals IR $v_{\max }(\mathrm{nu}-$ jol, $\left.\mathrm{cm}^{-1}\right): 1951$ (s, C=O), 2040 (s, C=O), 1921 (s, C=O), 1608 $(\mathrm{C}=\mathrm{O}), 1553,1511,1408,1306,1272$.

$\mathbf{1} \cdot\left[\mathrm{Mn}(\mathrm{CO})_{3} \mathbf{N}_{3}\right]$. Single crystals of $\mathbf{1} \cdot\left[\mathrm{Mn}(\mathrm{CO})_{3} \mathrm{Br}\right](30 \mathrm{mg})$ were washed with methanol $(5 \times 10 \mathrm{ml})$ with 30 minutes between each wash and transferred to a $20 \mathrm{ml}$ scintillation vial containing methanol $(5 \mathrm{ml})$. A $2 \mathrm{ml}$ glass vial containing $\mathrm{NaN}_{3}$ (30 mg) was placed inside the scintillation vial, and methanol was added such that the $2 \mathrm{ml}$ vial was fully submersed within the scintillation vial. The apparatus was left to stand at room temperature for $72 \mathrm{~h}$. The methanol solution was decanted and the MOF crystals washed thoroughly with methanol $(5 \times 10 \mathrm{ml})$ to yield $\mathbf{1} \cdot\left[\mathrm{Mn}(\mathrm{CO})_{3} \mathrm{~N}_{3}\right]$ as yellow crystals. IR: (nujol, $\mathrm{cm}^{-1}$ ): 2070 (s, N ), 2025 (s, CO), 1952 (s, CO), 1903 (s, CO), 1608 (s, C=O), 1555, 1510, 1408, 1303, 1272.

$\mathbf{1} \cdot\left[\mathrm{Mn}(\mathrm{CO})_{\mathbf{3}}(\mathbf{D M T})\right]$. Single crystals of $\mathbf{1} \cdot\left[\mathrm{Mn}(\mathrm{CO})_{3} \mathrm{~N}_{3}\right](30$ $\mathrm{mg})$ were washed with toluene $(5 \times 10 \mathrm{ml})$ and transferred to a Schlenk tube containing toluene $(5 \mathrm{ml})$ and dimethyl acetylene dicarboxylate $(0.1 \mathrm{ml})$. The mixture was sealed and heated at $50^{\circ} \mathrm{C}$ for $20 \mathrm{~h}$, after-which the solvent was decanted and the MOF crystals washed with fresh toluene $(5 \times 10 \mathrm{ml})$ to yield $\mathbf{1} \cdot\left[\mathrm{Mn}(\mathrm{CO})_{3}(\mathrm{DMT})\right]$ as pale yellow crystals. IR $v_{\max }\left(\right.$ nujol, $\mathrm{cm}^{-}$ ${ }^{1}$ ): 2034 (CO), 1956 (CO), 1909 (CO), 1716 (b, ester), 1608 (s, $\mathrm{C}=\mathrm{O}), 1554(\mathrm{C}=\mathrm{C}), 1509(\mathrm{C}=\mathrm{C}), 1406,1376,1302,1271,1169$ (w).

$\mathbf{1} \cdot\left[\mathbf{M n}(\mathbf{C O})_{3}(\mathbf{E T})\right]$. Single crystals of $\left.\mathbf{1} \cdot \mathrm{Mn}(\mathrm{CO})_{3} \mathrm{~N}_{3}\right](30$ $\mathrm{mg})$ were washed with toluene $(5 \times 10 \mathrm{ml})$ and transferred to a Schlenk tube containing toluene $(5 \mathrm{ml})$ and ethyl propiolate $(0.1$ $\mathrm{ml}$ ). The mixture was sealed and heated at $50^{\circ} \mathrm{C}$ for $20 \mathrm{~h}$, after which the solvent was decanted and the MOF crystals washed with fresh toluene $(5 \times 10 \mathrm{ml})$ to yield $\mathbf{1} \cdot\left[\mathrm{Mn}(\mathrm{CO})_{3}(\mathrm{ET})\right]$ as pale yellow crystals. IR $v_{\max }\left(\right.$ nujol, $\left.\mathrm{cm}^{-1}\right)$ : 2035 (CO), 1945 (CO), 1922 (CO), 1711 (ester), 1665 (C=O), 1554, 1408, 1303, 1272.

$1 \cdot\left[\mathrm{Mn}(\mathrm{CO})_{3}(4-h e x-5\right.$ '-ynl-1',4'-dione-1,2,3-triazolate)]. Single crystals of $\mathbf{1} \cdot\left[\mathrm{Mn}(\mathrm{CO})_{3} \mathrm{~N}_{3}\right](60 \mathrm{mg})$ were washed with toluene $(5 \times 10 \mathrm{ml})$ and transferred to a $8 \mathrm{ml}$ glass vial containing 1,7-octadiyne-3,6-dione (DA1). The mixture was sealed and heated at $50^{\circ} \mathrm{C}$ for $20 \mathrm{~h}$, after-which the solvent was decanted and the MOF crystals washed with fresh toluene $(5 \times 5$ $\mathrm{ml})$ to yield $1 \cdot\left[\mathrm{Mn}(\mathrm{CO})_{3}(\mathrm{HT})\right]$ as pale yellow crystals. IR $v_{\max }$ (nujol, $\mathrm{cm}^{-1}$ ): $2093(\mathrm{C} \equiv \mathrm{C}), 2035$ (CO), 1940 (CO), 1928 (CO), 1683 (ketone), 1555, 1458, 1303, 1272.

$1 \cdot\left[\mathrm{Mn}(\mathrm{CO})_{3}(4-o c t a-7\right.$ '-ynl-1',6'-dione-1,2,3-triazolate)]. Single crystals of $\mathbf{1} \cdot\left[\mathrm{Mn}(\mathrm{CO})_{3} \mathrm{~N}_{3}\right](60 \mathrm{mg})$ were washed with toluene $(5 \times 10 \mathrm{ml})$ and transferred to a $8 \mathrm{ml}$ glass vial containing 1,9-decadiyne-3,8-dione (DA2). The mixture was sealed and heated at $50^{\circ} \mathrm{C}$ for $20 \mathrm{~h}$, after-which the solvent was decanted and the MOF crystals washed with fresh toluene $(5 \times 5$ $\mathrm{ml})$ to yield $1 \cdot\left[\mathrm{Mn}(\mathrm{CO})_{3}(\mathrm{OT})\right]$ as pale yellow crystals. IR $v_{\max }$ (nujol, $\mathrm{cm}^{-1}$ ): 2089 (C $\left.\equiv \mathrm{C}\right), 2034$ (CO), 1938 (CO), 1917 (CO), 1671 (ketone), 1554, 1304, 1273.

$1 \cdot\left[\mathrm{Mn}(\mathrm{CO})_{3}(4-h e x-9 '-y n l-1 ', 8\right.$ '-dione-1,2,3-triazolate)]. Single crystals of $\mathbf{1} \cdot\left[\mathrm{Mn}(\mathrm{CO})_{3} \mathrm{~N}_{3}\right](60 \mathrm{mg})$ were washed with toluene $(5 \times 10 \mathrm{ml})$ and transferred to a $8 \mathrm{ml}$ glass vial containing 1,11-dodecadiyne-3,10-dione (DA3). The mixture was 
sealed and heated at $50^{\circ} \mathrm{C}$ for $20 \mathrm{~h}$, after-which the solvent was decanted and the MOF crystals washed with fresh toluene $(5 \times$ $5 \mathrm{ml})$ to yield $\mathbf{1} \cdot\left[\mathrm{Mn}(\mathrm{CO})_{3}(\mathrm{DT})\right]$ as pale yellow crystals. IR $v_{\max }$ (nujol, $\mathrm{cm}^{-1}$ ): 2091 (C $\left.\equiv \mathrm{C}\right), 2036$ (CO), 1956 (CO), 1903 (CO), 1672 (ketone), 1554, 1509, 1454, 1408, 1302, 1271.

Alkylation of MOF-bound triazolate (general procedure) and re-formation of $1 \cdot\left[\mathrm{Mn}(\mathrm{CO})_{3}\left(\mathrm{H}_{2} \mathrm{O}\right)\right] \mathrm{Br}$. Single crystals of $\mathbf{1} \cdot\left[\mathrm{Mn}(\mathrm{CO})_{3}(\mathrm{DMT})\right], \quad \mathbf{1} \cdot\left[\mathrm{Mn}(\mathrm{CO})_{3}(\mathrm{ET})\right]$, $\mathbf{1} \cdot\left[\mathrm{Mn}(\mathrm{CO})_{3}(\mathrm{HT})\right], \mathbf{1} \cdot\left[\mathrm{Mn}(\mathrm{CO})_{3}(\mathrm{OT})\right]$, and $\mathbf{1} \cdot\left[\mathrm{Mn}(\mathrm{CO})_{3}(\mathrm{DT})\right]$ (approx. $60 \mathrm{mg}$ ) were washed with toluene $(5 \times 10 \mathrm{ml})$ followed by dichloromethane $(30 \mathrm{ml})$ and $\mathrm{CDCl}_{3}(5 \mathrm{ml})$. The sample was added to $\mathrm{CDCl}_{3}(2 \mathrm{ml})$ in an $8 \mathrm{ml}$ glass vial with Teflon cap, degassed with $\mathrm{Ar}$ and cooled to $-10^{\circ} \mathrm{C}$ in an ice-salt bath. Simultaneously, $\mathrm{MeBr}$ was cooled to $-78^{\circ} \mathrm{C}$ and an excess poured into the vial containing the MOF under flow of Ar. The vial was sealed and heated to $50^{\circ} \mathrm{C}$ for $20 \mathrm{~h}$. The sample was cooled to room temperature, the MOF crystals were isolated via filtration and washed with $\mathrm{CDCl}_{3} \quad(5 \mathrm{ml})$ to yield $\mathbf{1} \cdot\left[\mathrm{Mn}(\mathrm{CO})_{3}\left(\mathrm{H}_{2} \mathrm{O}\right)\right] \mathrm{Br}$ as yellow single crystals. IR $v_{\max }$ (nujol, $\mathrm{cm}^{-1}$ ): 2040 (s, CO), 1951 (s, CO), 1921 (s, CO), 1606, 1553, 1510, 1493, 1408, 1305, 1272, 1182.

The filtrate containing $\mathrm{N}$-methylated triazole from the above reaction could be directly analyzed by NMR spectroscopy and mass spectrometry and subsequently evacuated under reduced pressure to yield the triazole compound(s) as oils for IR spectroscopy analysis when possible.

Dimethyl N(1)-methyl-4,5-carboxy-1,2,3-triazole (MeDMT). ${ }^{1} \mathrm{H}$ NMR (500 MHz, $\left.\mathrm{CDCl}_{3}\right): 4.28$ (s, 3H, N-CH $), 4.02$ (s, $\left.3 \mathrm{H}, \mathrm{COOCH}_{3}\right), 3.99$ (s, $\left.3 \mathrm{H}, \mathrm{COOCH}_{3}\right) ;{ }^{13} \mathrm{C} \mathrm{NMR}(150 \mathrm{MHz}$, $\left.\mathrm{CDCl}_{3}\right)$ : $163.11\left(\mathrm{CO}_{2}\right.$, ester), $161.48\left(\mathrm{CO}_{2}\right.$ ester), 142.81 (triazole), 132.69 (triazole), $63.15\left(\mathrm{CH}_{3}\right), 56.04\left(\mathrm{CH}_{3}\right.$ ester $), 55.39$ $\left(\mathrm{CH}_{3}\right.$ ester); IR (Nujol, $\left.\mathrm{cm}^{-1}\right): 1733 \mathrm{~cm}^{-1}(\mathrm{C}=\mathrm{O}), 1555 \mathrm{~cm}^{-1}$, 1262, 1228, 1179, 1124, 1063; m/z: 199.0590 (calc'd 199.0593).

Ethyl N-methyl-4-carboxy-1,2,3-triazole (Me-ET). Isomers a, b in 5:3 ratio respectively. ${ }^{1} \mathrm{H}$ NMR $\left(500 \mathrm{MHz}, \mathrm{CDCl}_{3}\right)$ : 8.13 (s, 1H, triazole $\mathrm{CH}(\mathrm{a})), 8.04$ (s, $1 \mathrm{H}$, triazole (b)), 4.44 (q, 2H, ester $\mathrm{CH}_{2}$ (b)), 4.41 (q, 2H, ester $\mathrm{CH}_{2}$ (a)), 4.34 (s, 3H, $\mathrm{CH}_{3}$ (a)), 4.28 (s, 3H, $\mathrm{CH}_{3}$ (b)), 1.42 (t, 3H, ester $\mathrm{CH}_{3}$ (b)), 1.41 (t, $3 \mathrm{H}$, ester $\left.\mathrm{CH}_{3}(\mathrm{a})\right)$.

N-Methyl 4-hex-5'-ynl-1',4'-dione-1,2,3-triazole. N2 and $\mathrm{N} 3$ Isomers in a 1:0.8 ratio respectively.

N2-Methyl-4-hexa-5'-ynl-1',4'-dione-1,2,3-triazole: $\quad{ }^{1} \mathrm{H}$ NMR $\left(600 \mathrm{MHz}, \mathrm{CDCl}_{3}\right): 8.03(\mathrm{~s}, 1 \mathrm{H}$, triazole $\mathrm{CH}), 4.27(\mathrm{~s}, 3 \mathrm{H}$, $\left.\mathrm{CH}_{3}\right), 3.36\left(\mathrm{t}, 2 \mathrm{H}, \mathrm{CH}_{2}\right), 3.27(\mathrm{~s}, 1 \mathrm{H}, \mathrm{C} \equiv \mathrm{C}-\mathrm{H}), 3.08(\mathrm{t}, 2 \mathrm{H}$, $\mathrm{CH} 2) ;{ }^{13} \mathrm{C}$ NMR (150 MHz, $\left.\mathrm{CDCl}_{3}\right): 191.53(\mathrm{C}=\mathrm{O}), 185.16$ $(\mathrm{C}=\mathrm{O}), 146.26$ (triazole), 135.10 (triazole $\mathrm{CH}), 81.10$ (alkyne), 78.96 (alkyne), $42.25\left(\mathrm{CH}_{3}\right), 38.41\left(\mathrm{CH}_{2}\right), 30.05\left(\mathrm{CH}_{2}\right)$.

N3-Methyl-4-hexa-5'-ynl-1 ',4'-dione-1,2,3-triazole: $\quad{ }^{1} \mathrm{H}$ NMR $\left(600 \mathrm{MHz}, \mathrm{CDCl}_{3}\right): 8.23(\mathrm{~s}, 1 \mathrm{H}$, triazole $\mathrm{CH}), 4.31(\mathrm{~s}, 3 \mathrm{H}$, $\left.\mathrm{CH}_{3}\right), 3.32$ (s, 1H, C $\left.\equiv \mathrm{C}-\mathrm{H}\right), 3.25\left(\mathrm{t}, 2 \mathrm{H}, \mathrm{CH}_{2}\right), 3.09\left(\mathrm{t}, 2 \mathrm{H}, \mathrm{CH}_{2}\right)$; ${ }^{13} \mathrm{C}$ NMR (150 MHz, $\left.\mathrm{CDCl}_{3}\right)$ : $187.69(\mathrm{C}=\mathrm{O}), 184.49(\mathrm{C}=\mathrm{O})$, 137.61 (triazole $\mathrm{CH}$ ), 132.89 (triazole), $80.88(\mathrm{C} \equiv \mathrm{C}), 79.56$ $(\mathrm{C} \equiv \mathrm{C}), 38.66\left(\mathrm{CH}_{3}\right), 38.04\left(\mathrm{CH}_{2}\right), 34.14\left(\mathrm{CH}_{2}\right)$.

Analysis of mixture: IR (Nujol, $\left.\mathrm{cm}^{-1}\right): 3249(\mathrm{C} \equiv \mathrm{C}-\mathrm{H}), 2958$ (C-H), 2919 (C-H), $2850(\mathrm{C}-\mathrm{H}), 2091(\mathrm{C} \equiv \mathrm{C}), 1680(\mathrm{C}=\mathrm{O})$, 1608, 1403, 1105; $\mathrm{m} / \mathrm{z}: \quad[\mathrm{M}+\mathrm{H}]^{+} \quad$ 192.0967(calc'd $\left.[\mathrm{M}+\mathrm{H}]^{+} 192.0773\right)$.

N-Methyl 4-octa-8'-ynl-1',6'-dione-1,2,3-triazole. Isomers a, b in a 1:0.8 ratio respectively. ${ }^{1} \mathrm{H}$ NMR $(600 \mathrm{MHz}$, $\mathrm{CDCl}_{3}$ ): 8.16 (s, triazole), 8.04 (s, triazole), 8.02 (s, triazole), $4.32\left(\mathrm{~s}, \mathrm{CH}_{3}\right), 4.26\left(\mathrm{~s}, \mathrm{CH}_{3}\right), 4.17\left(\mathrm{~s}, \mathrm{CH}_{3}\right), 3.24(\mathrm{~s}, \mathrm{C} \equiv \mathrm{C}-\mathrm{H})$, $3.22(\mathrm{~s}, \mathrm{C} \equiv \mathrm{C}-\mathrm{H}), 2.92\left(\mathrm{~m}, \mathrm{CH}_{2}\right), 2.68\left(\mathrm{CH}_{2}\right), 1.77\left(\mathrm{~m}, \mathrm{CH}_{2}\right) ;{ }^{13} \mathrm{C}$ NMR (150 MHz, $\left.\mathrm{CDCl}_{3}\right): 189.81(\mathrm{C}=\mathrm{O}), 186.52(\mathrm{C}=\mathrm{O})$, $185.57(\mathrm{C}=\mathrm{O}), 137.53$ (triazole), 135.16 (triazole), 133.55 (triazole), 126.23 (triazole), $81.28(\mathrm{C} \equiv \mathrm{C}), 78.72(\mathrm{C} \equiv \mathrm{C}), 78.67$ $(\mathrm{C} \equiv \mathrm{C}), 78.53(\mathrm{C} \equiv \mathrm{C}), 45.15\left(\mathrm{CH}_{2}\right), 45.01\left(\mathrm{CH}_{2}\right), 44.96\left(\mathrm{CH}_{2}\right)$, $40.61\left(\mathrm{CH}_{2}\right), 39.23\left(\mathrm{CH}_{2}\right), 38.97\left(\mathrm{CH}_{2}\right), 38.08\left(\mathrm{CH}_{3}\right), 36.99$ $\left(\mathrm{CH}_{3}\right), 23.20\left(\mathrm{CH}_{2}\right), 22.99\left(\mathrm{CH}_{2}\right), 22.92\left(\mathrm{CH}_{2}\right), 22.77\left(\mathrm{CH}_{2}\right)$; IR (Nujol, $\left.\mathrm{cm}^{-1}\right): 3238(\mathrm{C} \equiv \mathrm{C}-\mathrm{H}), 2089(\mathrm{C} \equiv \mathrm{C}), 1678(\mathrm{C}=\mathrm{O}), 1525$, 1448, 1397, 1368, 1261, 1104; m/z: $220.1130[\mathrm{M}+\mathrm{H}]^{+}$(calc'd $[\mathrm{M}+\mathrm{H}]^{+}$220.1091).

N-Methyl 4-deca-9'-ynl-1',8'-dione-1,2,3-triazole. Mixture of 8 isomers, signals identified as corresponding to triazole products are listed below. ${ }^{1} \mathrm{H}$ NMR $\left(600 \mathrm{MHz}, \mathrm{CDCl}_{3}\right): 8.16$ (three singlet signals, triazole $\mathrm{CH}), 8.03(\mathrm{~s}$, triazole $\mathrm{CH}), 8.01$ (three singlet signals, triazole $\mathrm{CH}), 4.31\left(\mathrm{~s}, \mathrm{CH}_{3}\right), 4,25\left(\mathrm{~s}, \mathrm{CH}_{3}\right)$, $4.15\left(\mathrm{~s}, \mathrm{CH}_{3}\right), 3.21$ (two singlets, $\left.\mathrm{C} \equiv \mathrm{C}-\mathrm{H}\right), 3.20(\mathrm{~s}, \mathrm{C} \equiv \mathrm{C}-\mathrm{H})$, $3.11\left(\mathrm{t}, \mathrm{CH}_{2}\right), 2.96\left(\mathrm{t}, \mathrm{CH}_{2}\right), 2.87\left(\mathrm{~m}, \mathrm{CH}_{2}\right), 2.58\left(\mathrm{~m}, \mathrm{CH}_{2}\right), 1.74$ (m, $\left.\mathrm{CH}_{2}\right), 1.69\left(\mathrm{~m}, \mathrm{CH}_{2}\right), 1.42\left(\mathrm{~m}, \mathrm{CH}_{2}\right), 1.38\left(\mathrm{~m}, \mathrm{CH}_{2}\right)$; IR (Nujol, $\left.\mathrm{cm}^{-1}\right): 3249(\mathrm{C} \equiv \mathrm{C}-\mathrm{H}), 2089(\mathrm{C} \equiv \mathrm{C}), 1682(\mathrm{C}=\mathrm{O}), 1609$ $(\mathrm{C}=\mathrm{O}), 1408,1306 ; \mathrm{m} / \mathrm{z}: 248.1421[\mathrm{M}+\mathrm{H}]^{+}\left(\right.$calc'd $[\mathrm{M}+\mathrm{H}]^{+}$ 248.1399).

\section{Computational Methods}

Density functional theory (DFT) calculations were carried out with the Gaussian 09 software package (Revision D.01) ${ }^{67}$ using the M06 functional. ${ }^{68}$ Geometry optimizations were carried out in vacuo using the SDD effective core potential ${ }^{69}$ for Mn ions and the 6-31G(d,p) basis set ${ }^{70}$ for all atoms. Singlepoint energies were also calculated for the optimized geometries with the 6-31+G(d,p) basis set and SMD continuum solvation model ${ }^{71}$ with toluene solvent. Calculations were carried out on a 306 -atom fragment of $\mathbf{1} \cdot\left[\mathrm{Mn}(\mathrm{CO})_{3}(\mathrm{DMT})\right]$ as a model for the extended MOF structure and on the corresponding molecular species $\left[\mathrm{Mn}(\mathrm{bpm})(\mathrm{CO})_{3}(\mathrm{DMT})\right]$. Geometry optimizations of the MOF fragments were carried out keeping all nonhydrogen atoms in the framework fixed at their positions in the experimental X-ray crystal structure except for the atoms in the immediate vicinity of the $\mathrm{Mn}(\mathrm{I})$ ion. The energy barrier to interconvert the $\mathrm{N}(1)$ - and $\mathrm{N}(2)$-bound complexes in $\mathbf{1} \cdot\left[\mathrm{Mn}(\mathrm{CO})_{3}(\mathrm{DMT})\right]$ was estimated from the energies of structures obtained by interpolating between the optimized N(1)and $\mathrm{N}(2)$-bound complexes and then optimizing the geometry with the orientation of the triazolate ring fixed with respect to the rest of the MOF. The computational procedures are described in further detail in the Supporting Information.

\section{Associated content}

Supporting information: characterization data for the MOF samples and related molecular species, characterization of triazole products, details of the SCXRD and tables of crystallographic data collection and refinement parameters, computational results, crystallographic information files (cifs).

\section{Acknowledgements}

CJD, CJS, DMH and NRC gratefully acknowledge the Australian Research Council for funding (DP160103234). Aspects of this research were undertaken on the MX1 and MX2 beamlines at the Australian Synchrotron, part of ANSTO, and made use of the Australian Cancer Research Foundation (ACRF) detector. DMH gratefully acknowledges computational resources provided by the Australian Government through the National Computing Infrastructure under the National Computational Merit Allocation Scheme and by the University of Adelaide's Phoenix High-Performance Computing service. MTH, AL and 
HG acknowledge the University of Adelaide and the Australian Government for a Research Training Program PhD scholarship.

\section{References}

(1) Furukawa, H.; Cordova, K. E.; O'Keeffe, M.; Yaghi, O. M. Science 2013, 341, 974.

(2) Yaghi, O. M.; O'Keeffe, M.; Ockwig, N. W.; Chae, H. K.; Eddaoudi, M.; Kim, J. Nature 2003, 423, 705.

(3) Huang, Y. B.; Liang, J.; Wang, X. S.; Cao, R. Chem. Soc. Rev. 2016, 46, 126. 2392.

(4) Dhakshinamoorthy, A.; Garcia, H. ChemSusChem. 2014, 7,

(5) Dhakshinamoorthy, A.; Asiri, A. M.; Garcia, H. Angew. Chem., Int. Ed. 2016, 55, 5414.

(6) Kitagawa, S.; Kitaura, R.; Noro, S. Angew. Chem., Int. Ed. 2004, $43,2334$.

(7) Ferey, G. Chem. Soc. Rev. 2008, 37, 191.

(8) Inokuma, Y.; Yoshioka, S.; Ariyoshi, J.; Arai, T.; Hitora, Y.; Takada, K.; Matsunaga, S.; Rissanen, K.; Fujita, M. Nature 2013, 495, 461.

(9) Dechnik, J.; Sumby, C. J.; Janiak, C. Cryst. Growth Des. 2017, 17, 4467.

(10) Dechnik, J.; Gascon, J.; Doonan, C. J.; Janiak, C.; Sumby, C. J. Angew. Chem., Int. Ed. 2017, 56, 9292.

(11) Seoane, B.; Coronas, J.; Gascon, I.; Benavides, M. E.; Karvan, O.; Caro, J.; Kapteijn, F.; Gascon, J. Chem. Soc. Rev. 2015, 44, 2421.

(12) Mason, J. A.; Veenstra, M.; Long, J. R. Chem. Sci. 2014, 5, 32.

(13) Doonan, C.; Riccò, R.; Liang, K.; Bradshaw, D.; Falcaro, P. Acc. Chem. Res. 2017, 50, 1423.

(14) Riccò, R.; Liang, W.; Li, S.; Gassensmith, J. J.; Caruso, F.; Doonan, C.; Falcaro, P. ACS Nano 2018, 12, 13.

(15) Stassen, I.; Burtch, N.; Talin, A.; Falcaro, P.; Allendorf, M.; Ameloot, R. Chem. Soc. Rev. 2017, 46, 3185.

(16) Dou, J.-H.; Sun, L.; Ge, Y.; Li, W.; Hendon, C. H.; Li, J.; Gul, S.; Yano, J.; Stach, E. A.; Dincă, M. J. Am. Chem. Soc. 2017, 139, 13608.

(17) Gonzalez, M. I.; Mason, J. A.; Bloch, E. D.; Teat, S. J.; Gagnon, K. J.; Morrison, G. Y.; Queen, W. L.; Long, J. R. Chem. Sci. 2017, 8, 4387.

(18) Bloch, E. D.; Queen, W. L.; Krishna, R.; Zadrozny, J. M.; Brown, C. M.; Long, J. R. Science 2012, 335, 1606.

(19) Sung Cho, H.; Deng, H.; Miyasaka, K.; Dong, Z.; Cho, M.; Neimark, A. V.; Ku Kang, J.; Yaghi, O. M.; Terasaki, O. Nature 2015, $527,503$.

(20) Bloch, W. M.; Burgun, A.; Coghlan, C. J.; Lee, R.; Coote, M. L.; Doonan, C. J.; Sumby, C. J. Nat. Chem. 2014, 6, 906.

(21) Bloch, W. M.; Burgun, A.; Doonan, C. J.; Sumby, C. J. Chem. Сотmun. 2015, 51, 5486.

(22) Huxley, M. T.; Coghlan, C. J.; Bloch, W. M.; Burgun, A.; Doonan, C. J.; Sumby, C. J. Phil. Trans. R. Soc. A 2017, 375, 20160028.

(23) Bloch, W. M.; Champness, N. R.; Doonan, C. J. Angew. Chem., Int. Ed. 2015, 54, 12860 .

(24) Duplan, V.; Hoshino, M.; Li, W.; Honda, T.; Fujita, M. Angew. Chem., Int. Ed. 2016, 55, 4919.

(25) Ikemoto, K.; Inokuma, Y.; Rissanen, K.; Fujita, M. J. Am. Chem. Soc. 2014, 136, 6892

(26) Fortea-Pérez, F. R.; Mon, M.; Ferrando-Soria, J.; Boronat, M.; Leyva-Pérez, A.; Corma, A.; Herrera, J. M.; Osadchii, D.; Gascon, J.; Armentano, D.; Pardo, E, Nature Mat. 2017, 16, 760.

(27) Burgun, A.; Coghlan, C. J.; Huang, D. M.; Chen, W.; Horike, S.; Kitagawa, S.; Alvino, J. F.; Metha, G. F.; Sumby, C. J.; Doonan, C. J. Angew. Chem., Int. Ed. 2017, 56, 8412 .

(28) Evans, J. D.; Sumby, C. J.; Doonan, C. J. Chem. Soc. Rev. 2014, 43, 5933.

(29) Fiandanese, V.; Maurantonio, S.; Punzi, A.; Rafaschieri, G. G. Org. Biomol. Chem. 2012, 10, 1186. 537
6035 .

(32) Tang, J.-L.; Ming, L.; Zhao, X.-M. J. Heterocycl. Chem. 2016, $53,1367$.

(33) Bettison, R. M.; Hitchcock, P. B.; Walton, D. R. M. J. Organomet. Chem. 1987, 341, 247.

(34) Shultz, A. M.; Farha, O. K.; Hupp, J. T.; Nguyen, S. T. J. Am. Chem. Soc. 2009, 131, 4204.

(35) Henry, L.; Schneider, C.; Mutzel, B.; Simpson, P. V.; Nagel, C.; Fucke, K.; Schatzschneider, U. Chem. Commun. 2014, 50, 15692.

(36) Bravo, J.; Castro, J. A.; Freijanes, E.; García-Fontán, S.; Lamas, E. M.; Rodríguez-Seoane, P. Z. Anorg. Allg. Chem. 2005, 631, 2067.

(37) Ault, B. S.; Becker, T. M.; Li, G. Q.; Orchin, M. Spectrochim. Acta, Part A 2004, 60, 2567.

(38) Simpson, P. V.; Skelton, B. W.; Raiteri, P.; Massi, M. New J. Chem. 2016, 40, 5797.

(39) Bauer, J. A. K.; Becker, T. M.; Orchin, M. J. Chem. Crystallogr. 2004, 34, 843 .

(40) Totobenazara, J.; Burke, A. J. Tetrahedron Lett. 2015, 56, 2853.

(41) Wang, C.; Ikhlef, D.; Kahlal, S.; Saillard, J.-Y.; Astruc, D. Coord. Chem. Rev. 2016, 316, 1

(42) Fehlhammer, W. P.; Beck, W. Z. Anorg. Allg. Chem. 2015, 641, 1599

(43) Astruc, D.; Liang, L.; Rapakousiou, A.; Ruiz, J. Acc. Chem. Res. 2012, 45, 640 .

(44) Arseneault, M.; Wafer, C.; Morin, J. F. Molecules 2015, 20 , 9263.

(45) Reck, F.; Zhou, F.; Girardot, M.; Kern, G.; Eyermann, C. J.; Hales, N. J.; Ramsay, R. R.; Gravestock, M. B. J. Med. Chem. 2005, $48,499$.

(46) Tron, G. C.; Pirali, T.; Billington, R. A.; Canonico, P. L.; Sorba, G.; Genazzani, A. A. Med. Res. Rev. 2008, 28, 278.

(47) Hein, C. D.; Liu, X. M.; Wang, D. Pharm. Res. 2008, 25, 2216.

(48) Thirumurugan, P.; Matosiuk, D.; Jozwiak, K. Chem. Rev. 2013, 113

(49) Tuci, G.; Rossin, A.; Xu, X.; Ranocchiari, M.; van Bokhoven, J. A.; Luconi, L.; Manet, I.; Melucci, M.; Giambastiani, G. Chem. Mat. 2013, 25, 2297

(50) Jiang, H.-L.; Feng, D.; Liu, T.-F.; Li, J.-R.; Zhou, H.-C. J. Am Chem. Soc. 2012, 134, 14690 .

(51) Goto, Y.; Sato, H.; Shinkai, S.; Sada, K. J. Am. Chem. Soc 2008, 130,14354

(52) Ko, T.; Kim, K.; Jung, B.-K.; Cha, S.-H.; Kim, S.-K.; Lee, J.C. Macromolecules 2015, 48, 1104.

(53) Yigit, S.; Sanyal, R.; Sanyal, A. Chem. Asian J. 2011, 6, 2648

(54) Juan-Alcaniz, J.; Ferrando-Soria, J.; Luz, I.; Serra-Crespo, P.; Skupien, E.; Santos, V. P.; Pardo, E.; F.X, L. i. X.; Kapteijn, F.; Gascon, J. J. Catal. 2013, 307, 295.

(55) Luz, I.; Llabres i Xamena, F. X.; Corma, A. J. Catal. 2010, 276, 134

(56) Chassaing, S.; Sani Souna Sido, A.; Alix, A.; Kumarraja, M.; Pale, P.; Sommer, J. Chem. Eur. J. 2008, 14, 6713.

(57) Chao-Wan, C.; Gene-Hsiang, L. Organometallics 2003, 22, 3107.

(58) Singh, K. S.; Kreisel, K. A.; Yap, G. P. A.; Kollipara, M. R. J. Organomet. Chem. 2006, 691, 3509.

(59) Knott, S. A.; Templeton, J. N.; Durham, J. L.; Howard, A. M.; McDonald, R.; Szczepura, L. F. Dalton Trans. 2013, 42, 8132.

(60) Kemmerich, T.; Nelson, J.; Takach, N.; Boehme, H.; Jablonski, B.; Beck, W. Inorg. Chem. 1982, 21, 1226.

(61) Chen, C.-K.; Tong, H.-C.; Hsu Chen, C.-Y.; Lee, C.-Y.; Fong, Y. H.; Chuang, Y.-S.; Lo, Y.-H.; Lin, Y.-C.; Wang, Y. Organometallics 2009, 28, 3358 .

(62) Bloch, W. M.; Doonan, C. J.; Sumby, C. J. CrystEngComm 2013, 15,9663

(63) Potapov, A. S.; Khlebnikov, A. I. Polyhedron 2006, 25, 2683.

(64) Wilbur, J. M.; Bonner, B. A. J. Polym. Sci., Part A: Polym. Chem. 1990, 28, 3747.

(65) McPhillips, T.; McPhillips, S.; Chiu, H.; Cohen, A. E.; Deacon, A. M.; Ellis, P. J.; Garman, E.; Gonzalez, A.; Sauter, N. K. Phizackerley, R. P.; Soltis, S. M.; Kuhn, P, J. Synchrotron Rad. 2002, 9, 401 . 
66) Sheldrick, G. M. Acta. Crystallogr. C Struct. Chem. 2015, 71 3.

(67) Gaussian 09, revision D.01; Frisch, M. J. Frisch; Trucks , G. W.; Schlegel, H. B.; Scuseria, G. E.; Robb, M. A.; Cheeseman, J. R.; Scalmani, G.; Barone, V.; Petersson, G. A.; Nakatsuji, H.; Li, X.; Caricato, M.; Marenich, A.; Bloino, J.; Janesko, B. G.; Gomperts, R.; Mennuccim, B.; Hratchian, H. P.; Ortiz, J. V.; Izmaylov, A. F.; Sonnenberg, J. L.; Williams-Young, D.; Ding, F.; Lipparini, F.; Egidi, F.; Goings, J.; Peng, B.; Petrone, A.; Henderson, T.; Ranasinghe, D.; Zakrzewski, V. G.; Gao, J.; Rega, N.; Zheng, G.; Liang, W.; Hada, M.; Ehara, M.; Toyota, K.; Fukuda, R.; Hasegawa, J.; Ishida, M.; Nakajima, T.; Honda, Y.; Kitao, O.; Nakai, H.; Vreven, T.; Throssell, K.; Montgomery, J. A.; Peralta Jr., J. E.; Ogliaro, F.; Bearpark, M.; Heyd, J. J.; Broth- ers, E.; Kudin, K. N.; Staroverov, V. N.; Keith, T.; Kobayashi, R.; Normand, J.; Raghavachari, K.; Rendell, A.; Burant, J. C.; Iyengar, S. S.; Tomasi, J.; Cossi, M.; Millam, J. M.; Klene, M.; Adamo, C.; Cammi, R.; Ochterski, J. W.; Martin, R. L.; Morokuma, K.; Farkas, O.; Foresman, J. B.; Fox, D. J.; Gaussian Inc.: Wallingford CT, 2013.

(68) Zhao, Y.; Truhlar, D. G. Theor. Chem. Acc. 2008, 120, 215.

(69) Andrae, D.; Häußermann, U.; Dolg, M.; Stoll, H.; Preuß, H. Theor. Chim. Acta 1990, 77, 123.

(70) Ab Initio Molecular Orbital Theory; Hehre, W. J. R., L; Schleyer, P.V.R; Pople, J.A; Wiley: New York, 1986; 1st ed.

(71) Marenich, A. V.; Cramer, C. J.; Truhlar, D. G. J. Phys. Chem. B 2009, 113, 6378 .

\section{Table of contents graphic:}

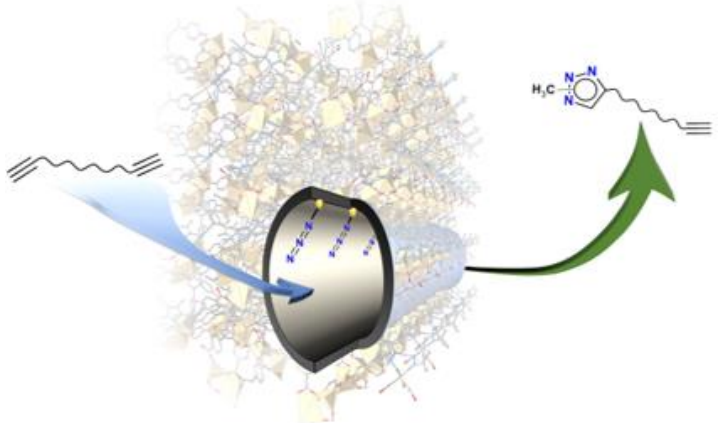

